\title{
Shape and Count of Free Graphite Particles in Thin Wall Ductile Iron Castings
}

\author{
Juan Miguel BORRAJO, Ricardo Antonio MARTíNEZ1), Roberto Enrique BOERI ${ }^{1)}$ and \\ Jorge Antonio SIKORA ${ }^{11}$
}

Graduate Student, División Metalurgia, INTEMA, CONICET, Fac, de Ingeniería, UNMdP Av. Juan B. Just 4302, (B7608 FDQ) Mar del Plata, Argentina. $\quad$ 1) División Metalurgia, INTEMA, CONICET, Fac. de Ingeniería, UNMdP Av. Juan B. Justo 4302, (B7608FDQ) Mar del Plata, Argentina. Email: jmborra@fi.mdp.edu.ar

(Received on July 24, 2001; accepted in final form on November 22, 2001)

\begin{abstract}
Recently, the scientific community has begun to study in detail the potential application of ductile iron in the production of thin wall components. Efforts are focused on the identification of the operative conditions necessary to obtain parts free of defects, with the desired microstructure. These aspects have been widely examined in the past for parts of conventional thickness (more than $5 \mathrm{~mm}$ ), either experimentally or by using computational programs to model the solidification process. Nevertheless, modeling of thin walled parts is still unreliable, since specific databases are not available.

The objective of this work is to study the evolution of the graphite nodule count and shape in ductile iron, as the section thickness diminishes down to $1.5 \mathrm{~mm}$, using conventional casting procedures and resin bonded sand molds.

A reasonably accurate correlation between solidification time and nodule count has been developed, based on experimental and modeled cooling curves. The morphology of graphite nodules has been characterized by image analysis, and the results correlated with the solidification time. The advantages of using solidification time as a parameter instead of thickness are also discussed.
\end{abstract}

KEY WORDS: thin wall ductile iron; nodule count; graphite shape; prediction.

\section{Introduction}

Modeling of casting processes using personal computer (PC) includes aspects such as filling of molds, heat transfer and evaluation of defects. Nowadays, foundrymen follow closely these developments to optimize casting processes, to reduce costs and to improve product quality. In the particular case of Ductile Iron (DI), models are aimed to predict nodule count (NC), microstructure, and consequently mechanical properties, prior to production.

Applications of ductile cast iron continue to increase steadily over the years due to its relatively low-cost production, its ease of recycling, and the capability to be produced with a wide range of microstructures and mechanical properties. Recently, increasing attention is being given to the production of thin wall ductile iron castings, in an attempt to extend the use of DI to the construction of components with high strength to weight ratios. ${ }^{1)}$ If the mechanical properties and flawless nature of standard wall thickness ductile iron castings could be sustained for thin wall ductile iron, it would be possible to increase its number of applications. In fact, the higher strength ductile iron grades have strength to weight ratios that are high enough to allow the replacement of aluminum in low weight-high strength parts.

It is well known that noticeable increments of nodule count take place when the cooling rate increases, for exam- ple as a consequence of the presence of thin walls. This effect is shown in Figs. 1(A) and 1(B), for plates of different thickness cast from the same melt in the metal casting laboratory of the Metallurgy Division of INTEMA. Figure 1(A) shows the microstructure of a $20 \mathrm{~mm}$ plate, which has a nodule count of approximately $150 \mathrm{nod} / \mathrm{mm}^{2}$, while Figure 1(B) corresponds to a plate of $2 \mathrm{~mm}$ in thickness with a nodule count higher than $2000 \mathrm{nod} / \mathrm{mm}^{2}$. This noticeable increment in nodule count is caused by the greater undercooling that takes place during solidification of the thinner sections, which activates a larger number of substrates for heterogeneous nucleation of graphite.

The nodule count is commonly referred to as a parameter of the quality of ductile iron. The increase in the nodule count can have an important effect on the solid-state phase transformations of ductile iron, and on its microstructure and mechanical properties.

The available information regarding the change in the nodule count as the section thickness decreases is still insufficient, particularly in the case of very thin wall sections. The objective of this work is to study the evolution of the nodule count and nodule shape in DI, as the section thickness diminishes down to about $1.5 \mathrm{~mm}$, for castings made using conventional melting and pouring procedures, and cast into resin bonded sand molds. 


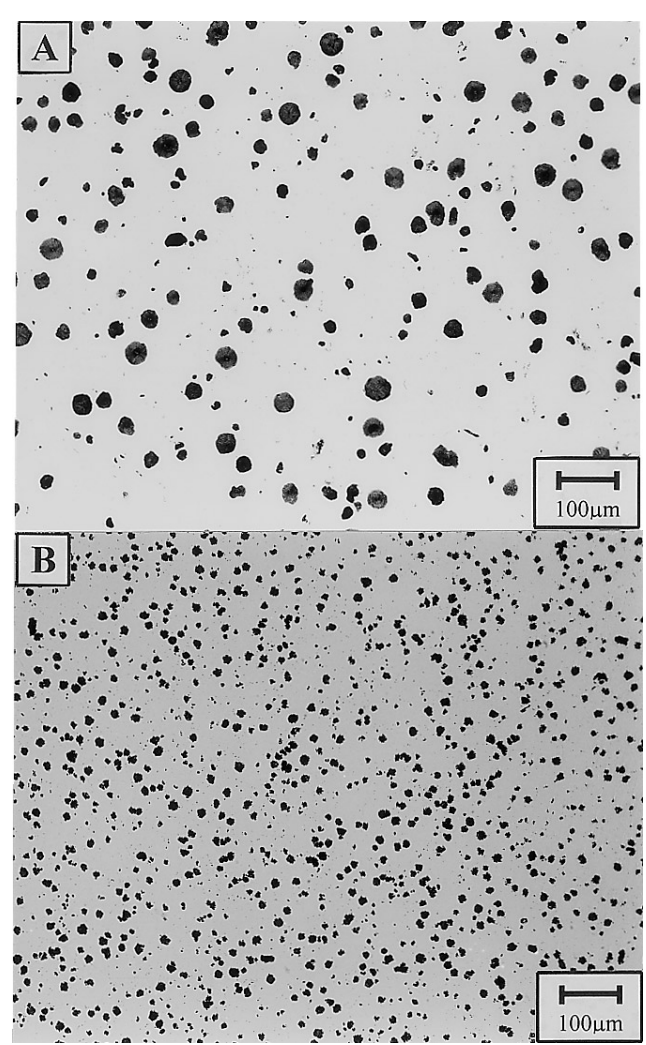

Fig. 1. Influence of section thickness on nodule count (unetched specimens). A: $20 \mathrm{~mm}$ plate $\left(150 \mathrm{nod} / \mathrm{mm}^{2}\right)$, B: $2 \mathrm{~mm}$ plate $\left(2000 \mathrm{nod} / \mathrm{mm}^{2}\right)$.

\section{Experimental Methods}

The melts were produced using a $60 \mathrm{~kg}$ medium frequency induction furnace. Steel scrap, low impurity pig iron and foundry returns were used as charge materials. The melts were treated with $2 \mathrm{wt} \%$ of $\mathrm{FeSi} \% \% \mathrm{MgCe}$ alloy $(20-40$ mesh) and inoculated with $0.6 \mathrm{wt} \%$ of Fe $75 \% \mathrm{Si}(5-15$ mesh), using the sandwich method and late inoculation. The metal was poured at approximately $1400^{\circ} \mathrm{C}$.

The shape and dimensions of the castings are shown in Fig. 2. These castings contain eight sections of different nominal thickness, ranging from 1.5 to $38.1 \mathrm{~mm}$. The difference in section thickness provides a considerable variation in cooling rate. An ASTM A 536-84 Y-block of 1/2" was also poured for each heat. Molds were prepared using alkydic resin bonded silica sands (60-62 mesh). The actual thickness of the different sections cast using the mold may be slightly different from nominal thickness. Therefore, the actual plate thickness, measured after casting, is used in tables and calculations.

The cooling curves corresponding to the geometrical center of each section of the specimens shown in Fig. 2, were recorded using uncovered $\mathrm{K}$ type thermocouples $(0.5$ and $1 \mathrm{~mm}$ in diameter), hooked to an 8-channel acquisition board installed in a PC. The temperatures were recorded until solid-state transformation temperature was overcome.

In order to obtain higher cooling rates, chills were positioned at the end of the thinner sections of some step blocks. Hypoeutectic, eutectic and hypereutectic alloys were produced. The chemical compositions are listed in Table 1.

The thermal evolution during the solidification of the
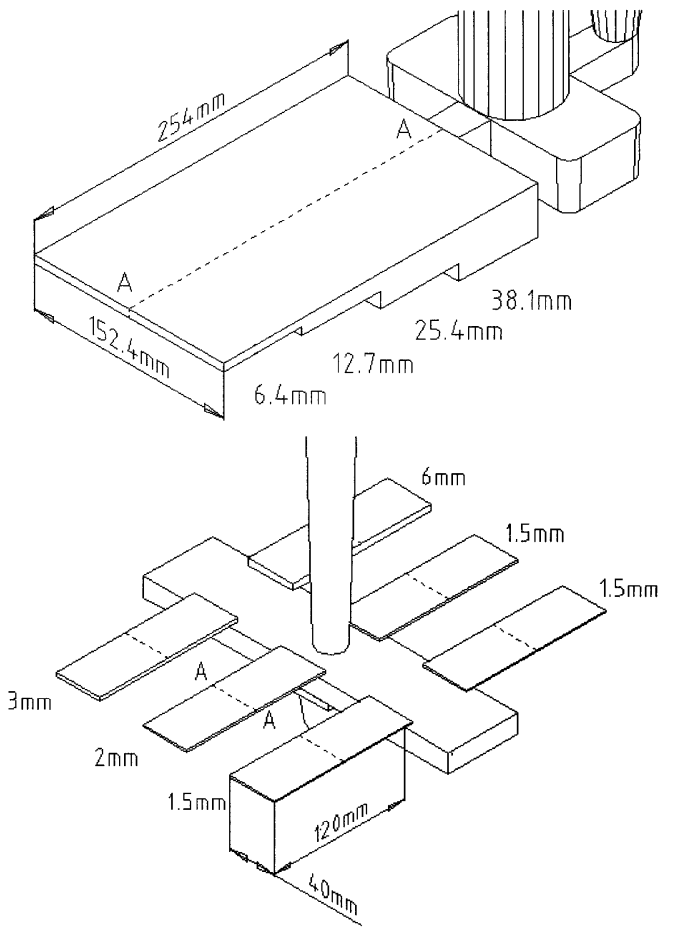

Fig. 2. Shape and dimensions of the test pieces. Temperature recording and metallographic specimens were taken from the geometric center of each section thickness.

castings was modeled by using the program named SIMTEC. Special attention was given to the heat evolution during the mold-filling step. This is considered critical for thin wall castings, where accurate temperature field calculations are heavily dependent on mold thermal history.

The solidification time at a given sample location $\left(t_{\mathrm{s}}\right)$ was estimated from the corresponding cooling curves. This was done on both recorded and modeled curves. The solidification time $\left(t_{\mathrm{s}}\right)$ was assumed to be the time interval between the tangent straight line to the curve at the start and at the end of solidification, as shown in Fig. 3.

The cooling curves of the thinner sections were difficult to measure, or were considered to be unreliable, due to the rapid cooling taking place at such sections and to the relatively slow response of the temperature acquisition set up. In these cases, only the modeled cooling curves were used to estimate the solidification time.

Metallographic specimens were taken from each section thickness of the castings by sectioning along lines A-A, shown in Fig. 2, and prepared using conventional polishing techniques.

Quantitative metallographic measurements were carried out using the Image-Pro Plus 1.3 analyzer, at a magnification of $100 \times$, with a pixel dimension of $0.91 \mu \mathrm{m}$. The nodule count was determined on unetched "as cast" specimens. Only particles having an area larger than $15 \mu \mathrm{m}^{2}$ were accounted for in the case of sample thickness larger than 10 $\mathrm{mm}$, while this limit was reduced to $8 \mu \mathrm{m}^{2}$ for the thinner wall thickness castings. The reported values correspond to the average of at least five measurements. The sphericity $(S)$, was calculated from the area and perimeter of nodules, by using Eq. (1). ${ }^{2}$ 
Table 1. Chemical composition (mass \%) of test pieces.

\begin{tabular}{|c|c|c|c|c|c|c|c|}
\hline & C & Si & Mn & P & S & Mg & $\begin{array}{c}\text { Carbon } \\
\text { Equivalent }\end{array}$ \\
\hline HO1 & 3.15 & 2.05 & 0.191 & 0.015 & 0.051 & 0.037 & 3.84 \\
\hline HO2 & 3.13 & 2.86 & 0.24 & 0.014 & 0.058 & 0.067 & 4.09 \\
\hline HO3 & 3.02 & 3.54 & 0.253 & 0.016 & 0.053 & 0.044 & 4.21 \\
\hline HO4 & 3.13 & 3.25 & 0.205 & 0.014 & 0.055 & 0.047 & 4.22 \\
\hline E1 & 3.28 & 2.94 & 0.221 & 0.015 & 0.051 & 0.043 & 4.27 \\
\hline E2 & 3.21 & 3.41 & 0.27 & 0.018 & 0.039 & 0.04 & 4.35 \\
\hline HE1 & 3.45 & 2.91 & 0.218 & 0.011 & 0.044 & 0.034 & 4.43 \\
\hline HE2 & 3.12 & 4.08 & 0.147 & 0.016 & 0.049 & 0.08 & 4.49 \\
\hline HE3 & 3.29 & 3.86 & 0.186 & 0.031 & 0.055 & 0.062 & 4.59 \\
\hline HE4 & 2.98 & 4.84 & 0.35 & 0.025 & 0.058 & 0.07 & 4.60 \\
\hline HE5 & 3.38 & 3.98 & 0.279 & 0.016 & 0.058 & 0.036 & 4.72 \\
\hline HE6 & 3.31 & 4.42 & 0.23 & 0.014 & 0.051 & 0.046 & 4.79 \\
\hline
\end{tabular}

* Carbon Equivalent (CE) calculated as $C E=C+\frac{S i}{3}+\frac{P}{5}$

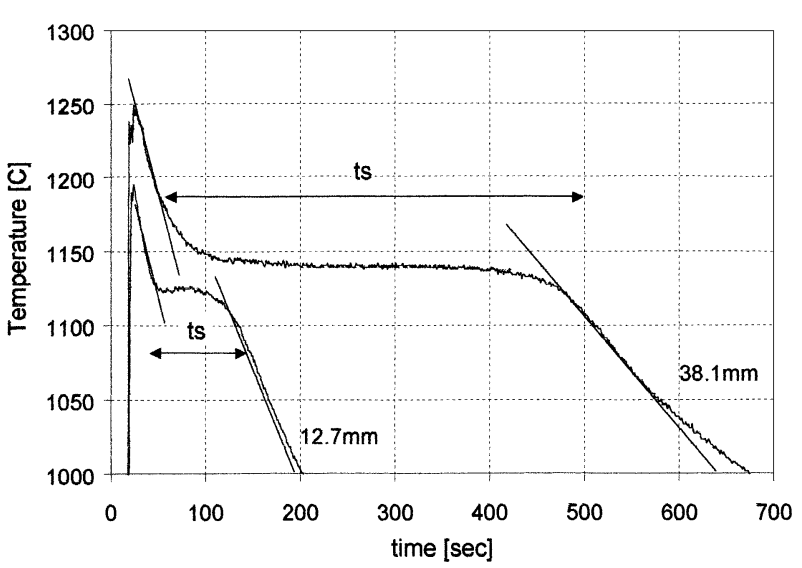

Fig. 3. Recorded cooling curves showing the measurement of solidification time.

$$
S=\text { Sphericity }=\frac{4 \cdot \pi \cdot \text { Area }}{(\text { Perimeter })^{2}}
$$

The average sphericity (AS), is calculated by averaging $S$ values of all nodules. Then, the nodularity by count (NBC\%) was established as:

$$
\mathrm{NBC}=\frac{\text { Number of acceptable particules }}{\begin{array}{c}
\text { Number of } \\
\text { acceptable }
\end{array}+\begin{array}{c}
\text { Number of } \\
\text { unacceptabel particules }
\end{array}} \cdot 100
$$

The nodules considered acceptable are those with sphericity values greater than 0.5 .

\section{Results and Discussion}

\subsection{Solidification Time}

The solidification time $\left(t_{\mathrm{s}}\right)$ was used as the variable parameter for the analysis of results, instead of the thickness. Correlations based on solidification time are more useful than those based on thickness, since results obtained for a given molding configuration can also be applied to other systems, which may include different mold materials, the presence of chills, etc. Even though solidification time is not easy to measure experimentally, particularly for thin sections, it can be calculated with reasonable accuracy by

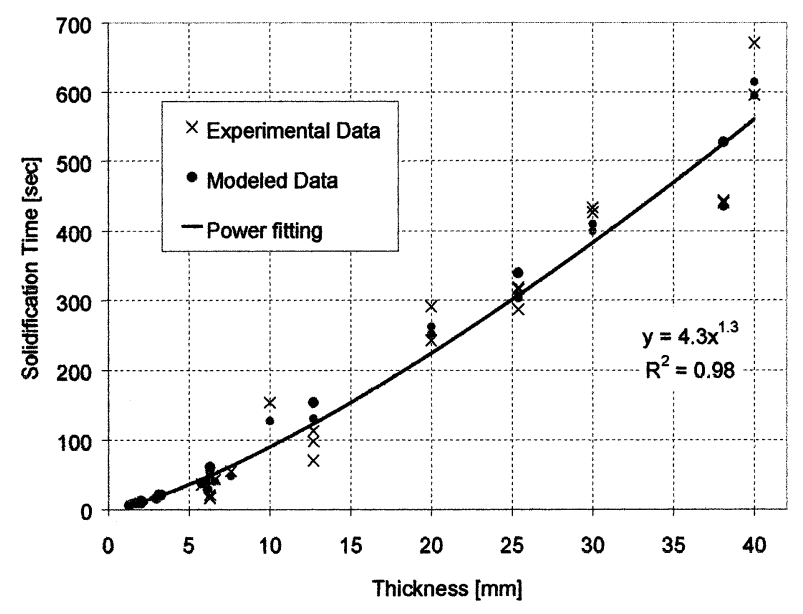

Fig. 4. Solidification time $v s$. thickness of sand cast plates. Both measured and calculated data points are shown by symbols. A correlation curve is also shown.

modeling, provided that boundary conditions are carefully selected and proper numerical treatment is used.

Figure 4 shows the values of $t_{\mathrm{s}}$, obtained from measured and calculated cooling curves, as a function of the thickness of the plate samples. The results based on calculations and on measurements are very similar and follow the same tendency. This supports the use of modeling to estimate the solidification time of the thinner sections, where actual measurements are not possible.

\subsection{Nodule Count}

The typical evolution of the nodule count (NC) as the section size diminishes is shown in Fig. 5, for samples of $1.5,3.0,12.7$ and $38.1 \mathrm{~mm}$ of thickness.

Tables 2, 3 and 4 list the results of nodule count as a function of solidification time, for hypoeutectic, eutectic and hypereutectic irons, respectively. The results are quite scattered. As expected, the hypoeutectic irons show lower nodule count, since they have a smaller amount of free graphite. Furthermore, the volume of free graphite in hypoeutectic compositions can be reduced for the smaller ts samples, as a result of the greater tendency to precipitate ledeburitic carbides. Hypoeutectic iron has lower graphitization potential, as a result of its smaller content of $\mathrm{C}$ and Si. 


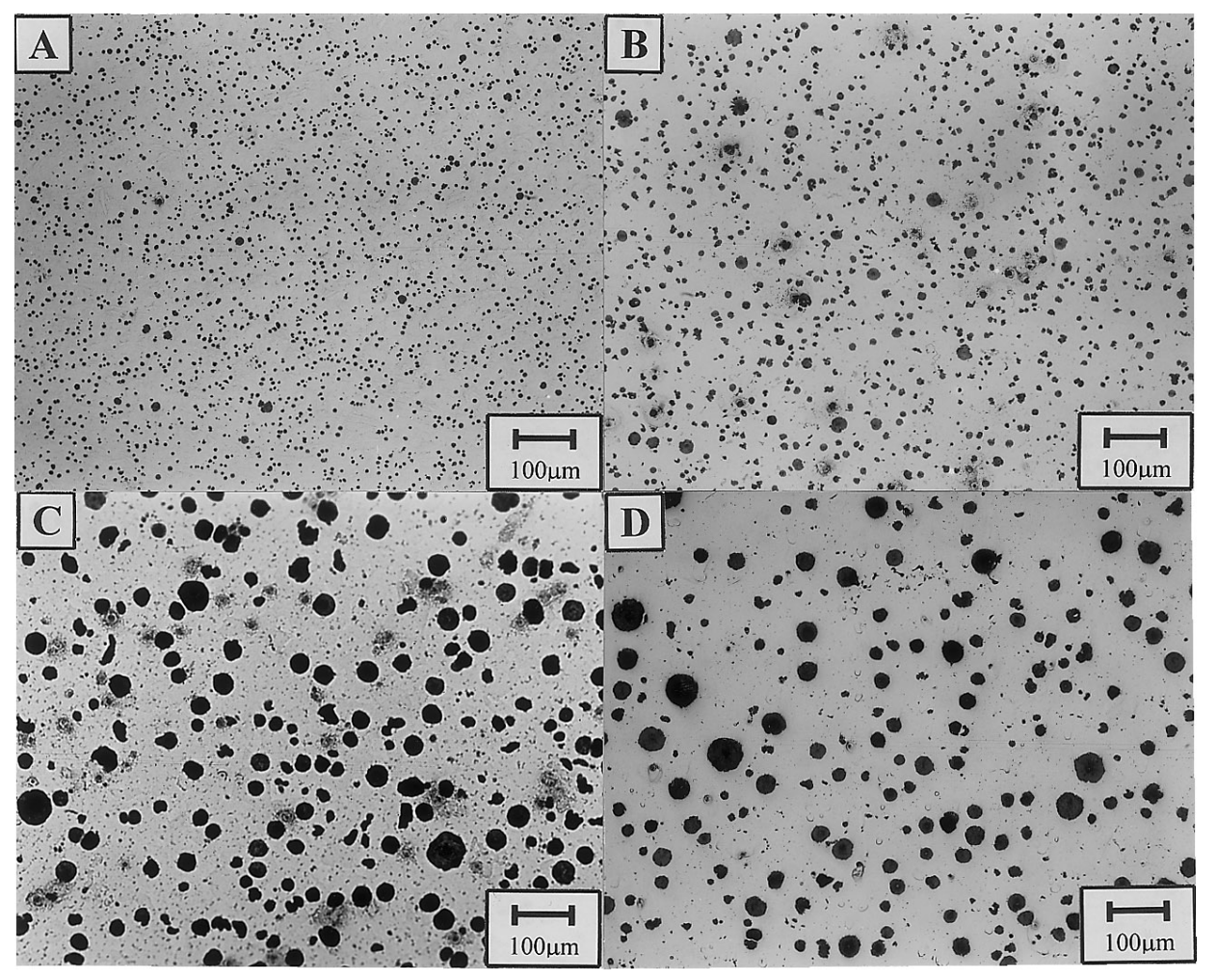

Fig. 5. Example of change in nodule count $(\mathrm{NC})$ for thickness values under study (unetched specimens, 100×). A: 1.5 $\mathrm{mm}, \mathrm{B}: 3.0 \mathrm{~mm}, \mathrm{C}: 12.7 \mathrm{~mm}$ and D: $38.1 \mathrm{~mm}$.

Table 2. Measured nodule count (NC) at corresponding solidification time $\left(t_{\mathrm{s}}\right)$, for hypoeutectic compositions (HO).

\begin{tabular}{|c|c|}
\hline ts [sec] & $\begin{array}{c}\mathrm{NC} \\
{\left[\mathrm{nod} / \mathrm{mm}^{2}\right]}\end{array}$ \\
\hline 441 & 123 \\
317 & 131 \\
254 & 235 \\
70.5 & 177 \\
57 & 294 \\
36 & 495 \\
17 & 434 \\
16.5 & 515 \\
9.3 & 505 \\
6 & 430 \\
5 & 819 \\
\hline
\end{tabular}

The $1.5 \mathrm{~mm}$ nominal thickness sections, which are characterized by solidification times smaller than $10 \mathrm{~s}$ (Fig. 4), have very high nodule counts, typically greater than 1000 nodules $/ \mathrm{mm}^{2}$ for eutectic and hypereutectic alloys, reaching values as high as 2400 nodules $/ \mathrm{mm}^{2}$.

\subsection{Shape of Graphite}

Tables 5, 6 and 7 show the results of AS and NBC, as well as the visual nodularity values estimated by using AFS charts (ASTM A 247-67). ${ }^{3)}$

It was found that, for the present experimental conditions, all specimens of ts smaller than $50 \mathrm{~s}$, corresponding to plates of thickness lower than $6 \mathrm{~mm}$, show average sphericity and nodularity higher than 0.80 or $90 \%$, respectively. This corresponds, approximately, to a visual nodularity (ASTM) equal to or greater than $80 \%$.

Figures 6 and 7 show the plot of AS and NBC as a function of solidification time. Although the results are quite scattered, both the nodularity (NBC) and the average
Table 3. Measured nodule count (NC) at corresponding solidification time $\left(t_{\mathrm{s}}\right)$, for hypereutectic compositions (HE).

\begin{tabular}{|c|c|}
\hline ts [sec] & $\begin{array}{c}\mathrm{NC} \\
{\left[\mathrm{nod} / \mathrm{mm}^{2}\right]}\end{array}$ \\
\hline 443.8 & 202 \\
287.5 & 162 \\
225 & 177 \\
98 & 228 \\
70 & 353 \\
55 & 798 \\
43 & 1127 \\
41 & 1007 \\
41 & 895 \\
19 & 1443 \\
19 & 1726 \\
18 & 887 \\
18 & 1275 \\
16.6 & 387 \\
11 & 1890 \\
10.5 & 722 \\
10 & 1836 \\
10 & 2423 \\
8 & 2027 \\
8 & 2413 \\
7 & 745 \\
\hline
\end{tabular}

sphericity (AS) increase as the solidification time decreases. AS and NBC vary within a similar range, of approximately $25 \%$, for the range of solidification time $\left(t_{\mathrm{s}}\right)$ examined.

\subsection{Correlations between Solidification Time and Graphite Characteristics}

Solidification time versus nodule count relationships have been shown to be best approximated by means of power law equations. ${ }^{4,5)}$ The following equation was used in this work: 
Table 4. Measured nodule count (NC) at corresponding solidification time $\left(t_{\mathrm{s}}\right)$, for eutectic compositions $(\mathrm{E})$.

\begin{tabular}{|c|c|}
\hline ts [sec] & $\begin{array}{c}\mathrm{NC} \\
{\left[\mathrm{nod} / \mathrm{mm}^{2}\right]}\end{array}$ \\
\hline 671 & 138 \\
596 & 216 \\
434 & 179 \\
427 & 236 \\
319 & 187 \\
292 & 176 \\
243 & 293 \\
154 & 351 \\
113 & 217 \\
29 & 854 \\
27.5 & 974 \\
23 & 1722 \\
23 & 1037 \\
21 & 434 \\
14 & 1110 \\
13.5 & 2249 \\
11 & 1145 \\
9.5 & 1971 \\
9.5 & 1257 \\
\hline
\end{tabular}

Table 5. Nodularity parameters: average sphericity (AS), nodularity by count (NBC) and nodularity (ASTM), at corresponding solidification Time $\left(t_{\mathrm{s}}\right)$, for hypoeutectic compositions (HO).

\begin{tabular}{|c|c|c|c|}
\hline $\begin{array}{c}\text { ts } \\
{[\mathrm{sec}]}\end{array}$ & AS & $\begin{array}{c}\text { NBC } \\
{[\%]}\end{array}$ & $\begin{array}{c}\text { ASTM } \\
{[\%]}\end{array}$ \\
\hline 441 & 0.83 & 91.49 & 80 \\
317 & 0.82 & 94.54 & 80 \\
254 & 0.80 & 89.26 & 70 \\
70.5 & 0.81 & 90.42 & 80 \\
57 & 0.79 & 89.11 & 70 \\
36 & 0.85 & 94.55 & $80-90$ \\
17 & 0.88 & 95.71 & 90 \\
16.5 & 0.93 & 99.30 & $90-100$ \\
9.3 & 0.93 & 95.31 & $90-100$ \\
6 & 0.94 & 96.09 & $90-100$ \\
5 & 0.87 & 96.22 & 80 \\
\hline
\end{tabular}

Table 6. Nodularity parameters: average sphericity (AS), nodularity by count (NBC) and nodularity (ASTM), at corresponding solidification time $\left(t_{\mathrm{s}}\right)$, for hypereutectic compositions (HE).

\begin{tabular}{|c|c|c|c|}
\hline $\begin{array}{c}\text { ts } \\
{[\mathrm{sec}]}\end{array}$ & AS & $\begin{array}{c}\text { NBC } \\
{[\%]}\end{array}$ & $\begin{array}{c}\text { ASTM } \\
{[\%]}\end{array}$ \\
\hline 443.8 & 0.84 & 93.84 & $80-90$ \\
287.5 & 0.82 & 90.85 & 80 \\
225 & 0.72 & 77.86 & 70 \\
98 & 0.82 & 93.45 & 80 \\
70 & 0.80 & 91.45 & 80 \\
55 & 0.89 & 96.63 & 90 \\
43 & 0.90 & 96.20 & 100 \\
41 & 0.81 & 92.69 & 80 \\
41 & 0.89 & 95.42 & $90-100$ \\
19 & 0.83 & 92.80 & 80 \\
19 & 0.91 & 96.59 & 90 \\
18 & 0.87 & 95.49 & $90-100$ \\
18 & 0.90 & 95.31 & 90 \\
16.6 & 0.88 & 96.93 & 90 \\
11 & 0.94 & 97.74 & 90 \\
10.5 & 0.89 & 93.12 & 100 \\
10 & 0.85 & 91.19 & 80 \\
10 & 0.95 & 98.31 & 100 \\
8 & 0.94 & 98.01 & \\
8 & 0.94 & 97.31 & 100 \\
7 & 0.86 & 89.38 & $80-90$ \\
& & & \\
\end{tabular}

Table 7. Nodularity parameters: average sphericity (AS), nodularity by count (NBC) and nodularity (ASTM), at corresponding solidification time (ts), for eutectic compositions (E).

\begin{tabular}{|c|c|c|c|}
\hline $\begin{array}{c}\text { ts } \\
{[\mathrm{sec}]}\end{array}$ & AS & $\begin{array}{c}\text { NBC } \\
{[\%]}\end{array}$ & $\begin{array}{c}\text { ASTM } \\
{[\%]}\end{array}$ \\
\hline 671 & 0.72 & 79.32 & 70 \\
596 & 0.74 & 87.27 & 70 \\
434 & 0.80 & 91.00 & 80 \\
427 & 0.80 & 91.47 & $70-80$ \\
319 & 0.76 & 84.59 & $70-80$ \\
292 & 0.70 & 76.15 & 60 \\
243 & 0.82 & 93.33 & 80 \\
154 & 0.87 & 95.23 & 80 \\
113 & 0.71 & 80.62 & 70 \\
29 & 0.89 & 95.59 & $90-100$ \\
27.5 & 0.88 & 96.16 & 90 \\
23 & 0.93 & 97.59 & 100 \\
23 & 0.92 & 96.40 & $90-100$ \\
21 & 0.81 & 90.36 & \\
14 & 0.92 & 96.79 & 100 \\
13.5 & 0.93 & 96.61 & 100 \\
11 & 0.93 & 97.32 & 100 \\
9.5 & 0.94 & 98.05 & 100 \\
9.5 & 0.92 & 97.14 & 100 \\
\hline
\end{tabular}

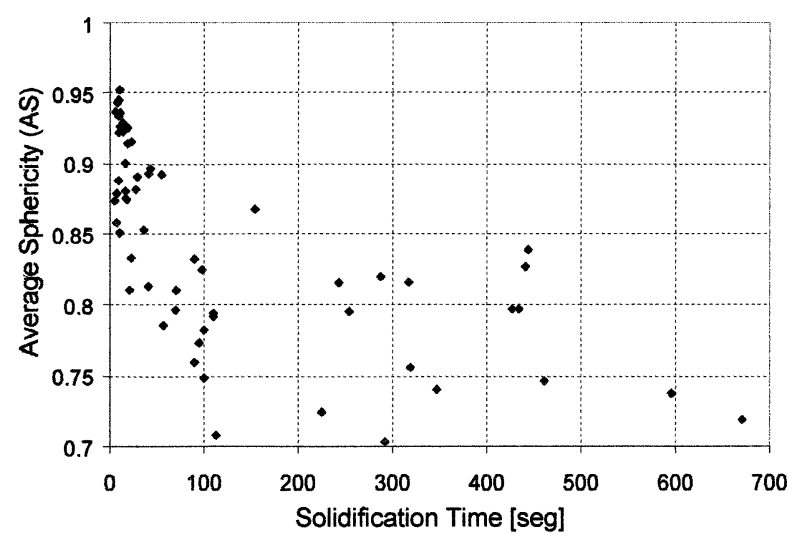

Fig. 6. Average sphericity as a function of the solidification time. Data collected for all specimens, regardless chemical composition and section thickness, are shown in the same plot.

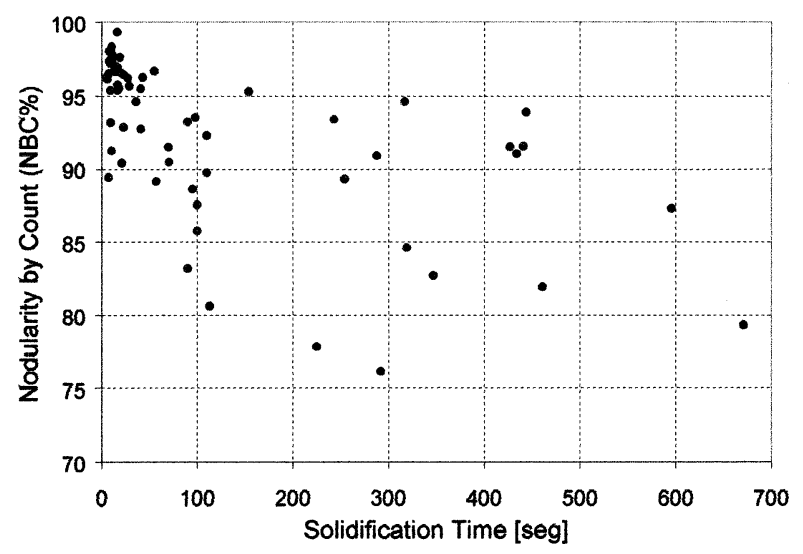

Fig. 7. Nodularity by count as a function of the solidification time. Data collected for all specimens, regardless chemical composition and section thickness, are shown in the same plot. 


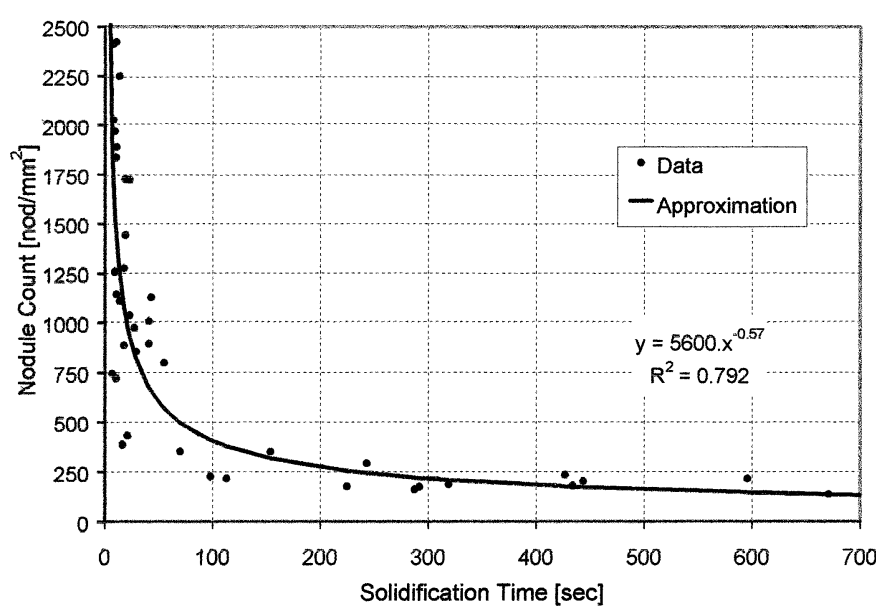

Fig. 8. Nodule count as a function of solidification time, for all hypereutectic and eutectic specimens.

$$
\mathrm{NC}=A \cdot t_{\mathrm{s}}^{-B}
$$

Where NC: nodule count [nodules $/ \mathrm{mm}^{2}$ ]

$$
t_{\mathrm{s}}: \text { solidification time }[\mathrm{s}]
$$

$A$ and $B$ : constants that take into account the effectiveness of the inoculation practice.

Equation (3) shows that the shorter the solidification time, the greater the nodule count, and the constants $A$ and $B$ determine how rapidly this takes place.

The data collected for each composition was used to estimate the values of the constants $A$ and $B$. The least-squares approximation method was used. The difference in the values of $A$ and $B$ for the hypereutectic and eutectic melts was small, while data for hypoeutectic compositions showed a considerable difference. Therefore, it seemed unreasonable to apply different equations for each composition, within the studied range. In consequence, hypereutectic and eutectic data points were used to obtain a single expression, as shown in Fig. 8. An equation for hypoeutectic melts was not developed.

The rate of change in nodule count becomes steeper as the solidification time drops below $50 \mathrm{~s}$. The scatter in the number of graphite particles for solidification rate of $50 \mathrm{~s}$ or less is higher than that for larger solidification times. This larger scatter may caused by the contribution of several factors, such as the difficulties associated to the measurement of high nodule counts, regarding the effect of polishing procedures and detection ranges, and the formation of free carbides in thinner sections, which reduces the amount of free graphite. The best fit was obtained by the following expression:

$$
\mathrm{NC}=5600 \cdot t_{\mathrm{s}}^{-0.57}
$$

This equation can be used to calculate, with reasonable approximation, the nodule count at a location of a given component, as a function of the solidification time. Its application is best suited to cast sections smaller than $30 \mathrm{~mm}$.

Values of nodule count as a function of solidification time, reported by Alagarsamy ${ }^{6}$ and Askeland--Grupta ${ }^{4)}$ for relatively thick sections, are compared with the predicted values obtained by Eq. (4), in Fig. 9. The predictions fit reasonably well to the higher limits of the ranges reported

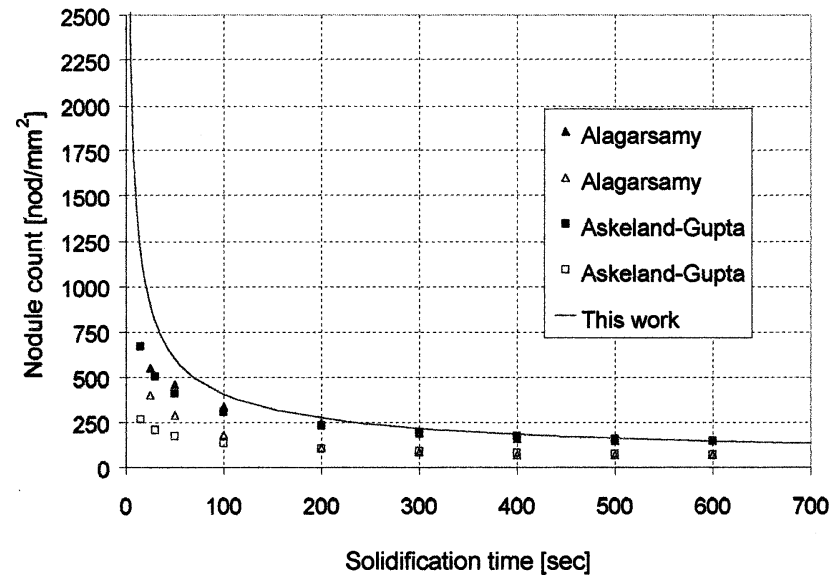

Fig. 9. Comparison of nodule count predictions and results of other authors. Open dots: lower limit. Solid dots: higher limit.

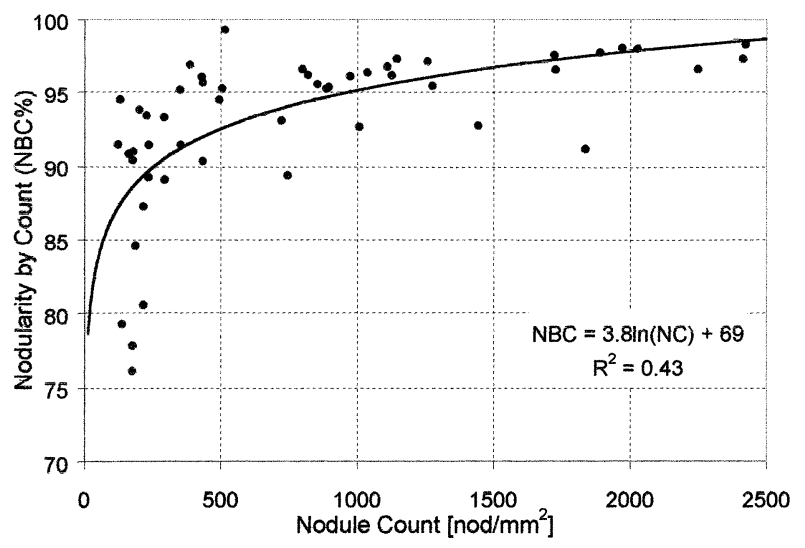

Fig. 10. Logarithmic regression for experimental data of nodularity by count $v s$. nodule count.

in the literature. The differences between calculated and measured values may be caused by a number of factors. The use of different graphite inoculation techniques can have a drastic effect on the nodule count of relatively thick sections. Furthermore, the methodology used to measure nodule counts can also lead to different results, particularly when automatic counting is carried out on high nodule count irons, through image analysis. In addition, the methodology used to measure solidification time is not necessarily equivalent to that applied in this investigation. Information for thinner sections has not been reported yet, to the best of our knowledge. Other authors reported the variation of nodule count as a function of thickness ${ }^{7-9)}$ or modulus, ${ }^{10)}$ but these data can not be used for comparison since the values of solidification time were not reported.

The variation of AS and NBC with nodule count, Figs. 6 and 7 , is too scattered and cannot be represented accurately by an equations. Nevertheless, the change in AS and NBC as a function of nodule count, shown in Figs. 10 and 11, show a relatively smaller scatter. The change in AS and $\mathrm{NBC}$ as a function of nodule count can be approximated by the following expressions;

$$
\begin{aligned}
& \mathrm{AS}=0.06 \cdot \ln (\mathrm{NC})+0.49 . \\
& \mathrm{NBC}=3.8 \cdot \ln (\mathrm{NC})+69 .
\end{aligned}
$$




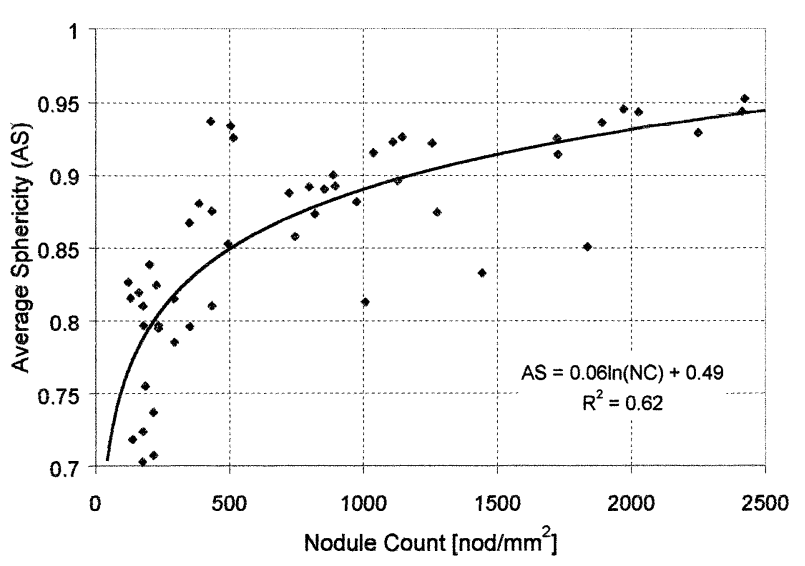

Fig. 11. Logarithmic regression for experimental data of average sphericity $v s$. nodule count.

Equations (4), (5) and (6) provide a satisfactory tool to estimate approximate values of count and shape of graphite nodules of thin wall ductile irons, as a function of the solidification time. These expressions can be used to build a routine that interacts with any properly set up solidification program, aimed to predict the characteristics of the graphite present in an actual ductile iron part.

\section{Conclusions}

(1) Hypoeutectic compositions show smaller nodule count than eutectic and hypereutectic irons, particularly when cast in small thickness sections. Meanwhile the rate of increase of nodule count as the section size diminishes is similar for both eutectic and hypereutectic ductile irons.

(2) Thin wall ductile iron castings show very large nod- ule counts. A reasonably accurate correlation has been developed to estimate the nodule count as a function of the solidification time. Calculations based on the correlation show good agreement with the results of others authors.

(3) Both the nodularity by count and the average sphericity increase as the section thickness decreases. Although data are rather scattered, logarithmic correlations were developed to calculate approximately the shape of graphite as a function of nodule count.

(4) Sections smaller than $6 \mathrm{~mm}$, having solidification time lower than $50 \mathrm{~s}$, show very high average sphericity and nodularity, higher than 0.80 and $90 \%$, respectively.

\section{REFERENCES}

1) K. G. Davis, M. Sahoo and A. Javaid: AFS Trans., 108 (2000), 191.

2) R. E. Ruxanda, D. M. Stefanescu and T. S. Piwonka: Proc. of the Int. Conf. on The Science of Casting and Solidification, ed. by D. Stefanescu, R. Ruxanda, M. Tierean and C. Serban, Editura Lux Libris, Brasov, Romania, (2001), 361.

3) Foundrymen's Guide to Ductile Iron Microstructures, AFS Publication, Illinois, (1984), 17.

4) D. R. Askeland and S. S. Gupta: AFS Trans., 83 (1975), 313.

5) J. Lacaze, M. Castro and G. Lesoult: Solidification of Spheroidal Graphite Cast Irons, Report no.13067, Centre Technique des Industries de la Fonderie, Sevres, (1998).

6) Al Algarasamy: Influence of Section Size on Microstructure and Mechanical Properties, Ductile Iron Handbook, ed. by M. Burditt, AFS, Illinois, (1992), 197.

7) F. Mampaey and Z. A. Xu: AFS Trans., 105 (1997), 95

8) D. M. Stefanescu, R. J. Warrick, L. R. Jenkins, G. Chen and F. Martínez: AFS Trans., 93 (1985), 835.

9) J. F. Wallace, P. Du, H-Q. Su, R. J. Warrick and L. R. Jenkins: $A F S$ Trans., 93 (1985), 813.

10) S. I. Karsay: Ductile Iron, State of the Art, QIT-Fer et Titane Inc., Montreal, Canada, (1980). 